\title{
Trends in off-label use of antipsychotic medications among Texas Medicaid children and adolescents from 2013 to 2016
}

\author{
Shuang Chen, MPH; Jamie C Barner, PhD; and Eun Cho, PhD
}

\section{What is already known about this subject}

- Antipsychotic use among the pediatric population increased in the late 1990s and early 2000s and then slightly tapered off as safety concerns gained attention since 2008 .

- A large proportion of children who received antipsychotic prescriptions did not have any FDA-approved indications.

\section{ABSTRACT}

BACKGROUND: Antipsychotics are frequently prescribed for off-label indications in the pediatric population. However, little is known regarding this issue in Texas Medicaid.

OBJECTIVES: To (1) describe off-label antipsychotic use among Texas Medicaid children and adolescents and (2) examine factors associated with off-label use.

METHODS: Texas Medicaid prescription and medical claims from January 2013 to August 2016 were analyzed retrospectively among subjects aged 2-17 years with an antipsychotic prescription. Three diagnostic status groups (on-label, off-label, no diagnosis) were categorized based on FDA-approved

\author{
What this study adds \\ - This study describes trends in and \\ factors associated with off-label \\ antipsychotic use among Texas \\ Medicaid children after 2011, which was \\ when several guidelines regarding off- \\ label antipsychotic use in children were \\ published. \\ - Off-label use of antipsychotics in \\ Texas Medicaid was prevalent but \\ declined during the 2013-2016 time \\ frame; however, of children receiving \\ antipsychotic off-label prescriptions, \\ over one-half had a diagnosis of \\ attention-deficit/hyperactivity disorder. \\ - Younger children and those prescribed \\ first-generation antipsychotics were \\ more likely to receive off-label \\ antipsychotic prescriptions.
}

indications. Descriptive and chi-square tests were conducted to determine if diagnostic status differed by age group (2-4, 5-9, 10-14, and $15-17$ years), sex, and antipsychotic type. A logistic regression analysis was used to identify factors associated with off-label use.

RESULTS: In this study, 43,792, 44,335, 37,221, and 24,879 (January-August) children with at least 1 antipsychotic prescription were identified from 2013 to 2016, respectively. The proportions with off-label use declined from $66.9 \%$ (2013) to $59.8 \%$ (2016). Among off-label users, more than one-half (51.3\%-55.8\%) had a diagnosis of attention-deficit/hyperactivity disorder. Less than $8 \%(6.0 \%-7.7 \%)$ of subjects had no mental health disorder diagnosis. Chisquare analyses (2015 data) revealed that the

\section{Author affiliations \\ Shuang Chen, $\mathrm{MPH}$, and Jamie C Barner, $\mathrm{PhD}$, College of Pharmacy, The University of Texas at Austin. Eun Cho, PhD, Sookmyung Women's University, Korea.}

\section{AUTHOR CORRESPONDENCE:}

Jamie C Barner, 512.471.5612

jbarner@austin.utexas.edu

J Manag Care Spec Pharm 2021;27(8):1035-45

Copyright $(2021$, Academy of Managed Care Pharmacy. All rights reserved.

proportion of off-label and no diagnosis users combined were significantly $(P<0.01)$ higher among users aged $5-9$ years $(82.5 \%)$ than adolescents $10-14$ years $(61.9 \%)$ and $15-17$ years (56.5\%); males (67.7\%) than females (65.3\%); and first-generation antipsychotics (FGAs; $79.3 \%$ ) than second-generation antipsychotics $(66.7 \%)$ users. Logistic regression analyses revealed younger age and FGA users had higher odds of off-label/no diagnosis use.

CONCLUSIONS: The proportion of off-label/ no diagnosis antipsychotic use declined from 2013 to 2016. Younger children and those receiving FGAs were more likely to be off-label antipsychotic users, with attentiondeficit/hyperactivity disorder being the most prevalent off-label diagnosis. 
Antipsychotic use among children and adolescents increased rapidly in the late 1990 s and early 2000 s and then tapered off as safety concerns gained attention. Studies using nationally representative survey data indicated a notable increase since the late 1990s, including a 6-fold increase in antipsychotic-related visits among children between 1993 and 2010.1-3 Among 3 Medicaid programs and a private managed care organization, the number of antipsychotic-treated children increased 1.5 to 3 times from 1996 to $2001 .{ }^{4}$ After a decade of growth, a slight decline in the prevalence of antipsychotic prescriptions among children was observed from 2008 to 2010 in a nationally representative claims database. ${ }^{5} \mathrm{~A}$ similar decline occurred among Medicaid recipients in the Northeast: antipsychotic use in Pennsylvania Medicaid beneficiaries decreased by $38.4 \%$ from 2008 to $2013,{ }^{6}$ and antipsychotic use in Vermont Medicaid beneficiaries decreased by $45 \%$ (age 6-12 years) and 27\% (age 13-17 years) from 2009 to 2012.?

Accompanied by the overall increase in antipsychotic use in the late 1990s, a shift from second-generation antipsychotics (SGAs) and first-generation antipsychotics (FGAs) occurred as SGAs gradually replaced FGAs. ${ }^{3,8-11}$ In fact, the vast majority of antipsychotic prescriptions in children (96.7\%-99\%) are SGAs. ${ }^{5,12}$ Since first approved in the 1990s, SGAs were predominantly prescribed in children due to lower treatment-emergent extrapyramidal side effects and cognitive impairment as compared with FGAs. ${ }^{13,14}$ However, SGAs were associated with increased cardiovascular risks, metabolic side effects such as weight gain and dyslipidemia, ${ }^{15}$ and an increased risk of unexpected death. ${ }^{13-16}$

In the pediatric population, antipsychotics have been approved for psychiatric disorders including schizophrenia, bipolar disorder, autistic disorder, and Tourette syndrome. However, in clinical practice, antipsychotics are frequently prescribed in this population for other mental health conditions (eg, attention-deficit/hyperactivity disorder [ADHD], disruptive behavioral disorders, and depression) that do not have an approved indication by the US Food and Drug Administration (FDA; ie, off-label use). As a vulnerable population, children are at risk for adverse effects (eg, antipsychotic-induced metabolic side effects), and there have been limited clinical trials using children to demonstrate the long-term efficacy and safety of antipsychotics. ${ }^{17}$

Increasing antipsychotic use in the late 1990s and early 2000s was largely attributed to the increase in off-label antipsychotic use. In a study using nationally representative survey data from 1995-1998 to 1999-2002, there was a 2.5-fold increase in on-label use, whereas for off-label use, there was a 3.5 -fold increase. ${ }^{2}$

In other studies using national representative survey data, more than half (51\%-82\%) of antipsychotics prescribed during office visits were for off-label use, and 12\%-15\% had no diagnosis. ${ }^{118}$ One study, which used physician survey data, revealed that $76 \%$ of SGAs and $55 \%$ of FGAs prescribed during an office visit were for off-label indications. ${ }^{3}$ Similarly, in a 42-state Medicaid study, off-label prescribing accounted for $75.9 \%$ of antipsychotic use among children and adolescents in 2003. ${ }^{19}$

In addition, $72.8 \%$ of antipsychotic use among Vermont Medicaid-enrolled children were off-label in 2012. ${ }^{7}$ In a multistate Medicaid study, the proportion of off-label use was stable from 2004 to 2013, as almost three-quarters of Medicaid youth were prescribed antipsychotics off-label in $2004 .^{20}$ The proportion of no mental health diagnosis was estimated to be from $9.1 \%$ to $13.0 \%$ in 2 Medicaid database studies. ${ }^{20,21}$ Of note was that no diagnosis could be intentional because of potential stigma issues related to documentation of mental health-related diagnoses. ${ }^{22,23}$

Since 2011, several guidelines addressed the widespread off-label use of antipsychotics. ${ }^{24-26}$ The Practice Parameter for the Use of Atypical Antipsychotic Medications in Children and Adolescents (AACAP-AAA), ${ }^{25}$ which focuses on children and adolescents aged 5-18 years, suggested that SGAs could be used as first-line treatment for FDA-approved indications. For other conditions, such as disruptive behavior disorder and ADHD, SGAs could be considered as secondline treatment after other pharmacological or psychosocial treatments have been attempted. ${ }^{25}$ Guidelines also emphasized the importance of follow-up monitoring for metabolic abnormalities..$^{16,25}$

To better manage psychotropic medication use in children, $88 \%$ of states used psychotropic medicationmonitoring programs. ${ }^{6}$ Texas Medicaid identified several conditions that should receive additional clinical review, including lack of an evaluation for the Diagnostic and Statistical Manual of Mental Disorders (DSM-5) diagnoses in the medical record or prescribing antipsychotics to very young children (aged $<4$ years).

Recent studies on off-label antipsychotic use in the pediatric population were primarily from nationally representative surveys. ${ }^{1,18}$ Previous research using Medicaid data was concentrated in the early 2000s. . $20,27,28$ Antipsychotic medication use patterns among Texas Medicaid youth in recent years is unknown, especially after psychotropic medication-monitoring programs commenced. Compared with children with private insurance, antipsychotic use is more prevalent in Medicaid-enrolled children, potentially in part because they have limited access to psychosocial interventions and higher rates of mental health conditions. ${ }^{29}$ In addition, Medicaid-enrolled children, who typically have low socioeconomic status, as well as high 
prevalence of obesity and other metabolic comorbidities, are more vulnerable to metabolic adverse effects associated with antipsychotic medications. ${ }^{20,30,31}$

The objectives of this study were to (1) examine the trends in off-label antipsychotic medication use among Texas Medicaid children from 2013 to 2016 and (2) determine if demographic and medication-related factors were associated with off-label use.

\section{Methods}

\section{DATA SOURCE}

This retrospective study included data from Texas Medicaid prescription and medical claims between January 1, 2013, and August 31, 2016 (latest available data). The prescription claims data included deidentified patient identification, sex, age, dispense dates, days of supply, drug name, generic code number (GCN), American Hospital Formulary Service (AHFS) Pharmacologic-Therapeutic Classification code and National Drug Code (NDC) number. Medical claims data included deidentified patient identification, encounter dates, and diagnosis codes (International Classification of Diseases, Ninth/Tenth Revision, Clinical Modification [ICD9/10-CM] codes).

\section{SAMPLE SELECTION}

Study subjects were children (aged 2-17 years) who received at least 1 prescription for an antipsychotic medication during the study period (January 1, 2013-August 31, 2016) and who were continuously enrolled for 1 year. For the trend analysis, which examined antipsychotic use in each calendar year, subjects could be represented in multiple years. The index date was the date of the first prescription claim for an antipsychotic agent.

For those who switched antipsychotics, an intent-totreat approach was used, and the index drug was used in the analysis. Patients on antipsychotic combination therapy $(\sim 3.0 \%)$, which was defined as 2 or more antipsychotics with an overlap for at least 6 weeks ( $\geq 42$ days), were excluded. ${ }^{10}$ In addition to complexities of determining on- vs offlabel use, these patients were excluded, since they may represent patients with higher disease severity and more comorbidities. ${ }^{32,33}$ In addition, patients who were prescribed 2 antipsychotics on the index date were excluded.

\section{OUTCOMES}

The primary outcome was the diagnosis status of the index antipsychotic prescription, which was categorized as onlabel, off-label, and no diagnosis. Patients were categorized as "on-label" if the index antipsychotic was associated with an FDA-approved mental health disorder diagnosis (Table 1) during the year and was in accordance with the age group for the patient. Patients were categorized as "off-label" if the index antipsychotic did not include 1 of the FDA-approved indications for the respective patient's age. The off-label group was further categorized into "supported use" and "unsupported use" according to AACAP-AAA practice guidelines and a drug compendium (ie, DrugDex), which provides strength of evidence for off-label use. ${ }^{3,34}$ Off-label use would be considered as supported use when an off-label indication was in accordance with an indication labeled "moderate or strong" evidence in DrugDex or supported by evidence in AACAP-AAA practice guidelines. ${ }^{25,35,36}$ Otherwise, the offlabel use was categorized as "unsupported use." Patients were categorized as "no diagnosis" if there were no mental health disorder diagnoses (ICD-9-CM codes 290-319 or ICD-10-CM codes F00-F99) documented during the same calendar year.

Diagnostic status was determined based on individual FDA-approved indications rather than the drug class because, according to the package insert of each medication, SGA medications with distinctive efficacy and safety are not interchangeable. ${ }^{25}$ For patients who had more than 1 mental health disorder diagnosis, the diagnosis closest to the index date was used to categorize them into the diagnostic status.

For patients in the on-label group, a hierarchical classifying approach was adopted if patients had more than 1 diagnosis on the same day, starting with schizophrenia, autistic disorder, bipolar disorder, and psychotic disorders..$^{20}$ However, for patients in the off-label group, all mental health diagnoses (ie, depression, autistic disorder, Tourette syndrome, anxiety, ADHD, disruptive behavior disorders, bipolar disorder, adjustment-related disorders, and other mental disorder diagnoses) were documented throughout the 1-year study period, and as such, patients could belong to more than 1 mental health disorder diagnosis category.

\section{INDEPENDENT VARIABLES}

Age and sex, as well as antipsychotic type (FGA vs SGA) were included as independent variables. To make the results comparable with previous studies, subjects were categorized into the following 4 age groups: 2-4 years, 5-9 years, 10-14 years, and $15-17$ years.

\section{STATISTICAL ANALYSIS}

Descriptive statistics were used to describe the trends in yearly proportion of diagnostic status, antipsychotic type, age, and sex over the study period (2013-2016). The yearly proportion of each diagnostic status (on-label, off-label, no diagnosis) was calculated by the number of patients in the 


\section{TABLE 1 Antipsychotics and FDA-Approved Indications}

Antipsychotics

FDA-approved indications for children (age group) ${ }^{a}$

First-generation antipsychotics ${ }^{b}$

\begin{tabular}{l|l}
\hline Chlorpromazine & $\begin{array}{l}\text { Schizophrenia (1-12 years) } \\
\text { Bipolar disorder, mania (1-12 years) } \\
\text { Behavioral problems (severe) }{ }^{c}(1-12 \text { years) }\end{array}$ \\
\hline Haloperidol & $\begin{array}{l}\text { Hyperactive behavior, after failure to respond to non-antipsychotic medication and psychotherapyc }(\geq 3 \text { years) } \\
\text { Problematic behavior in children (severe), after failure to respond non-antipsychotic medication or psychotherapyc } \\
(\geq 3 \text { years) } \\
\text { Schizophrenia/psychotic disorders ( } \geq 3 \text { years) } \\
\text { Tourette syndrome }(\geq 3 \text { years })\end{array}$ \\
\hline Loxapine & Schizophrenia ( $\geq 12$ years) \\
\hline Perphenazine & Schizophrenia ( $\geq 12$ years) \\
\hline Pimozide & Tourette syndrome ( $\geq 12$ years) \\
\hline Thiothixene & Schizophrenia ( $\geq 12$ years) \\
\hline
\end{tabular}

Second-generation antipsychotics ${ }^{\text {d }}$

\begin{tabular}{|c|c|}
\hline Aripiprazole & $\begin{array}{l}\text { Schizophrenia (13-17 years) } \\
\text { Bipolar I disorder (10-17 years) } \\
\text { Irritability with autistic disorder (6-17 years) } \\
\text { Tourette syndrome (6-18 years), approved December } 12,2014\end{array}$ \\
\hline Asenapine & Bipolar I disorder: manic or mixed (10-17 years) \\
\hline Olanzapine & $\begin{array}{l}\text { Schizophrenia (13-17 years) } \\
\text { Bipolar I disorder (10-17 years) }\end{array}$ \\
\hline Paliperidone & Schizophrenia (12-17 years) \\
\hline Quetiapine & $\begin{array}{l}\text { Schizophrenia (13-17 years) } \\
\text { Bipolar I disorder (10-17 years) }\end{array}$ \\
\hline Risperidone & $\begin{array}{l}\text { Schizophrenia ( } 13-17 \text { years) } \\
\text { Bipolar I disorder ( } 10-17 \text { years) } \\
\text { Irritability with autistic disorder ( } 5-17 \text { years) }\end{array}$ \\
\hline \multicolumn{2}{|c|}{$\begin{array}{l}{ }^{a} \text { Approved indications based on package insert and DrugDex. Fluphenazine, prochlorperazine, brexpiprazole, cariprazine, clozapine, iloperidone, lurasidone, and } \\
\text { ziprasidone were not approved for pediatric population. }\end{array}$} \\
\hline \multicolumn{2}{|c|}{$\begin{array}{l}\text { 'Behavioral problems were not considered FDA-approved indications in this analysis because of their ambiguous definition and lack of available data to assess if } \\
\text { children received psychotherapy service before receiving antipsychotics. Problematic behavior refers to combativeness or explosive hyperexcitable behavior or to } \\
\text { hyperactive children with excessive motor activity with accompanying conduct disorders. } \\
\text { dClass-level FDA-approved indications for SGAs: schizophrenia (12-17 years), bipolar disorder (10-17 years), irritability with autistic disorder (5-17 years), and } \\
\text { Tourette syndrome (6-17 years; since 2015). } \\
\text { FDA=US Food and Drug Administration; FGA = first-generation antipsychotics; SGA=second-generation antipsychotics. }\end{array}$} \\
\hline
\end{tabular}

corresponding group divided by all antipsychotic recipients. In addition to examining individual drug-level indications, a sensitivity analysis was conducted to examine diagnostic status at the drug class level (FGA vs SGA), which has been used by several other studies..$^{19,20}$ Thus, antipsychotic prescriptions were categorized as on-label if any drug within the class received approval (Table 1). For example, since risperidone was approved for treating autistic disorder for children aged 5 years and older, any SGA prescribed for children in that age category with an autistic disorder diagnosis was also considered as on-label use.

The bivariate relationships between diagnostic status and age group, sex, and antipsychotic type were analyzed using chi-square tests. Multivariable logistic regression 


\section{TABLE 2 Demographic and Clinical Characteristics of Children and Adolescents with Antipsychotic Prescriptions, 2013-2016}

\begin{tabular}{|c|c|c|c|c|c|c|c|c|}
\hline & \multicolumn{2}{|c|}{2013} & \multicolumn{2}{|c|}{2014} & \multicolumn{2}{|c|}{2015} & \multicolumn{2}{|c|}{$2016^{b}$} \\
\hline & \multicolumn{2}{|c|}{$(n=43,792)$} & \multicolumn{2}{|c|}{$(n=44,335)$} & \multicolumn{2}{|c|}{$(n=37,221)$} & \multicolumn{2}{|c|}{$(n=24,879)$} \\
\hline & $\mathbf{n}$ & $\%$ & $\mathbf{n}$ & $\%$ & $\mathbf{n}$ & $\%$ & $\mathbf{n}$ & $\%$ \\
\hline \multicolumn{9}{|l|}{ Age, years } \\
\hline $2-4$ & 2,040 & 4.7 & 1,533 & 3.5 & 901 & 2.4 & 199 & 0.8 \\
\hline $5-9$ & 15,204 & 34.7 & 14,284 & 32.2 & 11,162 & 30.0 & 6,567 & 26.4 \\
\hline $10-14$ & 17,851 & 40.8 & 18,568 & 41.9 & 16,187 & 43.5 & 11,576 & 46.5 \\
\hline $15-17$ & 8,697 & 19.9 & 9,950 & 22.4 & 8,971 & 24.1 & 6,537 & 26.3 \\
\hline \multicolumn{9}{|l|}{ Sex } \\
\hline Female & 14,355 & 32.8 & 15,246 & 34.4 & 12,839 & 34.5 & 8,004 & 32.2 \\
\hline Male & 29,437 & 67.2 & 29,089 & 65.6 & 24,382 & 65.5 & 16,875 & 67.8 \\
\hline \multicolumn{9}{|l|}{ Antipsychotic type } \\
\hline $\mathrm{FGA}$ & 459 & 1.1 & 545 & 1.2 & 510 & 1.4 & 347 & 1.4 \\
\hline SGA & 43,333 & 98.9 & 43,790 & 98.8 & 36,711 & 98.6 & 24,532 & 98.6 \\
\hline \multicolumn{9}{|l|}{ Diagnostic status } \\
\hline On label & 11,874 & 27.1 & 12,858 & 29.0 & 12,027 & 32.3 & 8,089 & 32.5 \\
\hline Off label & 29,304 & 66.9 & 28,474 & 64.2 & 22,962 & 61.7 & 14,878 & 59.8 \\
\hline Supported off-label use & 19,583 & 66.8 & 18,385 & 64.6 & 14,637 & 63.7 & 9,416 & 63.2 \\
\hline Unsupported off-label use & 9,721 & 33.2 & 10,089 & 35.4 & 8,325 & 36.3 & 5,462 & 36.8 \\
\hline No diagnosis & 2,614 & 6.0 & 3,003 & 6.7 & 2,232 & 6.0 & 1,912 & 7.7 \\
\hline
\end{tabular}

aThis output was based on excluding all patients on antipsychotic polypharmacy and on 2 or more index drugs before analysis.

'2016 data available from January 1 to August 31.

FGA = first-generation antipsychotics; SGA=second-generation antipsychotics.

analysis was performed to examine the association between independent variables (age group, sex, antipsychotic type) and diagnostic status (on vs off label). For this analysis, off-label use included patients labeled as off-label and those with no diagnoses. Although the trend analysis included all age groups, children aged 2-4 years were excluded from the inferential analyses (ie, chi-square and logistic regression), since no antipsychotic medication was approved for children aged less than 5 years, which would result in cell sizes of 0 .

For the trend analysis (data from 2013-2016), patients could be represented in multiple years. For chi-square tests and the logistic regression, only data for 2015 (latest full year data) were used, and patients were represented only once. All analyses were performed at the patient level. SAS version 9.4 (SAS Institute) was used for all data analyses. The study was approved by the University of Texas at Austin Institutional Review Board.

\section{Results}

\section{PARTICIPANTS}

During the years 2013 to 2016, 102,639 children aged 2-17 years received at least 1 antipsychotic prescription. After accounting for antipsychotic use and continuous enrollment during the study period, 65,444 (63.8\%) children remained. After excluding those who were on combination therapy or who had 2 antipsychotics prescribed on the index date, 63,290 (96.7\%) patients were identified between 2013 and 2016. Regarding each year's cohort, final sample sizes were 43,792 (2013), 44,335 (2014), 37,221 (2015), and 24,879 (January-August 2016 only).

\section{DESCRIPTIVE AND OUTCOME DATA}

Table 2 shows that in Texas Medicaid, patients who received antipsychotics increased from 43,792 to 44,335 between 2013 and 2014, then decreased to 37,221 in 2015. In 2016 (January and August), 24,879 antipsychotic-treated patients 


\section{TABLE 3 On-Label and Off-Label Diagnoses for Children and Adolescents with Antipsychotic Prescriptions, 2013-2016}

\begin{tabular}{|c|c|c|c|c|c|c|c|c|}
\hline \multirow[b]{3}{*}{ On-label diagnoses ${ }^{b}$} & \multicolumn{2}{|c|}{2013} & \multicolumn{2}{|c|}{2014} & \multicolumn{2}{|c|}{2015} & \multicolumn{2}{|c|}{$2016^{a}$} \\
\hline & \multicolumn{2}{|c|}{$(n=11,874)$} & \multicolumn{2}{|c|}{$(n=12,858)$} & \multicolumn{2}{|c|}{$(n=12,027)$} & \multicolumn{2}{|c|}{$(n=8,089)$} \\
\hline & $\mathbf{n}$ & $\%$ & $\mathbf{n}$ & $\%$ & $\mathbf{n}$ & $\%$ & $\mathbf{n}$ & $\%$ \\
\hline Bipolar disorder & 7,827 & 65.9 & 8249 & 64.2 & 7,512 & 62.5 & 4,753 & 58.8 \\
\hline Autistic disorder & 3,627 & 30.6 & 4133 & 32.1 & 4,046 & 33.6 & 3,041 & 37.6 \\
\hline Schizophrenia & 395 & 3.3 & 456 & 3.6 & 444 & 3.7 & 253 & 3.1 \\
\hline Tourette syndrome & 13 & 0.1 & 10 & 0.1 & 13 & 0.1 & 37 & 0.5 \\
\hline \multirow[t]{2}{*}{ Psychotic disorders } & 12 & 0.1 & 10 & 0.1 & 12 & 0.1 & 5 & 0.1 \\
\hline & \multicolumn{2}{|c|}{$(n=29,304)$} & \multicolumn{2}{|c|}{$(n=28,474)$} & \multicolumn{2}{|c|}{$(n=22,962)$} & \multicolumn{2}{|c|}{$(n=14,878)$} \\
\hline Off-label diagnoses ${ }^{c}$ & $\mathbf{n}$ & $\%$ & $\mathbf{n}$ & $\%$ & $\mathbf{n}$ & $\%$ & $\mathbf{n}$ & $\%$ \\
\hline ADHD & 15,436 & 52.7 & 14,606 & 51.3 & 11,847 & 51.6 & 8,302 & 55.8 \\
\hline Disruptive behavior disorders & 6,881 & 23.5 & 6,416 & 22.5 & 5,116 & 22.3 & 2,556 & 17.2 \\
\hline Unspecified mood disorder & 6,564 & 22.4 & 6,555 & 23.0 & 5,032 & 21.9 & 1,887 & 12.7 \\
\hline Depression & 2,915 & 9.9 & 3,127 & 11.0 & 2,554 & 11.1 & 1,412 & 9.5 \\
\hline Anxiety & 2,169 & 7.4 & 1,711 & 6.0 & 1,553 & 6.8 & 996 & 6.7 \\
\hline Bipolar disorder & 1,709 & 5.8 & 1,734 & 6.1 & 1,388 & 6.0 & 904 & 6.1 \\
\hline Psychotic disorders & 775 & 2.6 & 763 & 2.7 & 596 & 2.6 & 302 & 2.0 \\
\hline Autistic disorder & 521 & 1.8 & 583 & 2.0 & 555 & 2.4 & 386 & 2.6 \\
\hline Schizophrenia & 85 & 0.3 & 105 & 0.4 & 109 & 0.5 & 76 & 0.5 \\
\hline Tourette syndrome & 78 & 0.3 & 92 & 0.3 & 74 & 0.3 & 40 & 0.3 \\
\hline
\end{tabular}

a2016 data available from January 1 to August 31.

${ }^{b}$ Hierarchical classification approach was applied for on-label diagnoses ordered as (1) schizophrenia, (2) autistic disorder, (3) bipolar disorder, (4) Tourette syndrome, and (5) psychotic disorders. On-label diagnostic groups are mutually exclusive.

'Numbers for off-label diagnoses may total more than sum or more than $100 \%$ because off-label diagnostic groups are not mutually exclusive. Patients can have more than 1 diagnosis.

$A D H D=$ attention-deficit/hyperactivity disorder .

were included. Between 2013 and 2016, the proportion of antipsychotics prescribed decreased for children aged 2-4 and 5-9 years, while for adolescents (aged 10-14 and 15-17 years), the proportion increased. The most notable change occurred in children aged 2-4 years, where the proportion of antipsychotics declined by $83 \%-$ from $4.7 \%$ in 2013 to $0.8 \%$ in 2016. During the study period (2013-2016), the majority (65.5\%-67.8\%) of antipsychotic recipients were males, and more than $98.6 \%$ were on SGAs.

Table 2 also shows that most of the children and adolescents receiving antipsychotic prescriptions did not have an FDA-approved indication. The proportions with off-label use were $66.9 \%, 64.2 \%, 61.7 \%$, and $59.8 \%$, from 2013 to 2016, respectively, while the proportions with no diagnosis were $6.0 \%, 6.7 \%, 6.0 \%$, and $7.7 \%$, respectively. Of these offlabel uses, approximately two-thirds (63.2\%-66.8\%) were supported by evidence in practice guidelines or DrugDex. When we expanded the diagnostic status at the drug class level of FGA or SGA rather than drug level, results showed a slightly lower proportion ( 4-7 percentage points) of off-label antipsychotic use from 2013 to 2016: 63.1\%, 59.8\%, $56.0 \%$, and $53.2 \%$, respectively (data not shown).

In 2015, among all (on-label, off-label, no diagnosis) 37,221 antipsychotic-treated children and adolescents, ADHD (31.8\%) was the most common diagnosis, followed by bipolar disorder (23.9\%; data not shown). Table 3 shows prevalence of on-label and off-label diagnoses. As the most common on-label indication, bipolar disorder was diagnosed in more than half $(58.8 \%-65.9 \%)$ of children in the on-label group, followed by autistic disorders (30.6\%$37.6 \%)$. Less than $4 \%$ of children in the on-label group had a diagnosis of schizophrenia (3.1\%-3.6\%). Over half of 


\section{TABLE 4}

Chi-Square Comparison of Demographic and Clinical Characteristics and Antipsychotic On-Label vs Off-Label/No Diagnosis Use in $2015(\mathrm{~N}=36,320)$

\begin{tabular}{|c|c|c|c|c|c|c|c|}
\hline \multirow[b]{2}{*}{ Characteristics } & \multicolumn{2}{|c|}{ On-label } & \multicolumn{2}{|c|}{$\begin{array}{c}\text { Off-label/ } \\
\text { no diagnosis }\end{array}$} & \multicolumn{3}{|c|}{ Chi-square test } \\
\hline & $\mathbf{n}$ & row $\%$ & $\mathbf{n}$ & row \% & $x^{2}$ & df & $P$ value \\
\hline \multicolumn{8}{|l|}{ Age group, years } \\
\hline $5-9$ & 1,959 & 17.5 & 9,203 & 82.5 & \multirow{3}{*}{1837.9} & \multirow{3}{*}{3} & \multirow{3}{*}{$<0.01$} \\
\hline $10-14$ & 6,167 & 38.1 & 10,020 & 61.9 & & & \\
\hline $15-17$ & 3,901 & 43.5 & 5,070 & 56.5 & & & \\
\hline \multicolumn{8}{|l|}{ Sex } \\
\hline Male & 7,653 & 32.3 & 16,055 & 67.7 & \multirow{2}{*}{21.4} & \multirow{2}{*}{1} & \multirow{2}{*}{$<0.01$} \\
\hline Female & 4,374 & 34.7 & 8,238 & 65.3 & & & \\
\hline \multicolumn{8}{|c|}{ Antipsychotic type } \\
\hline FGA & 104 & 20.7 & 398 & 79.3 & \multirow{2}{*}{35.3} & \multirow{2}{*}{1} & \multirow{2}{*}{$<0.01$} \\
\hline SGA & 11,923 & 33.3 & 23,895 & 66.7 & & & \\
\hline
\end{tabular}

$\mathrm{df}=$ degree of freedom; $\chi^{2}=$ Pearson's chi square test; $F G A=$ first-generation antipsychotics; $S G A=$ second-generation antipsychotics.

children receiving antipsychotic offlabel prescriptions were diagnosed with ADHD (51.3\%-55.8\%), followed by disruptive behavior disorders (17.2\%23.5\%) and unspecified mood disorder (12.7\%-23.0\%).

\section{MAIN RESULTS}

The main analyses were conducted using 2015 data and off-label and no diagnosis groups were combined (ie, off-label use/no diagnosis) to form the dependent variable. Chisquare analysis (Table 4) showed that there was a significant relationship $(P<0.01)$ regarding the proportion of off-label use/no diagnosis between different age groups, with the highest among patients aged 5-9 years (82.5\%), followed by those aged 10-14 years $(61.9 \%)$ and $15-17$ years (56.5\%). Although small, males had a significantly $(\mathrm{P}<0.01)$ higher proportion of off-label use/no diagnosis compared with females (67.7\% vs $65.3 \%$, respectively). Finally, those prescribed FGAs had a significantly $(\mathrm{P}<0.01)$ higher proportion of off-label use/no diagnosis compared with those prescribed SGAs (79.3\% vs $66.7 \%$, respectively).

Logistic regression (Table 5) indicated that age group and antipsychotic type were significantly associated with the likelihood of off-label use/no diagnosis. Younger age and FGA users were more likely to receive antipsychotics off-label/ no diagnosis. Compared with adolescents aged 15-17 years, the odds of off-label/no diagnosis antipsychotic use were 3.66 times higher for children aged $5-9$ years $(\mathrm{P}<0.01$; odds ratio $[\mathrm{OR}]=3.66,95 \% \mathrm{CI}=3.43-3.91$ ) and 1.26 times higher for adolescents aged 10-14 years $(\mathrm{P}<0.01 ; \mathrm{OR}=1.26$, $95 \% \mathrm{CI}=1.19-1.33)$. The odds of offlabel use/no diagnosis antipsychotic use were $57 \%$ lower for SGA users compared with FGA users $(\mathrm{P}<0.01$; $\mathrm{OR}=0.43,95 \% \mathrm{CI}=0.35-0.54)$. No difference was observed for off-label/no diagnosis antipsychotic use between males and females $(P=0.67 ; \mathrm{OR}=0.99$, 95\% CI $=0.94-1.04)$.

\section{Discussion}

This study found that prevalent offlabel antipsychotic use among Texas Medicaid children and adolescents decreased slightly from $72.9 \%$ to $67.5 \%$ from 2013 to 2016. These results are similar to the range $(72.8 \%-75.9 \%)$ of other previous Medicaid studies regarding prevalence, as well as showing a decline over time. ${ }^{7,19,20}$ A multistate Medicaid study by Crystal et al showed that almost three-quarters of youth with antipsychotic prescriptions were prescribed antipsychotics off label in $2004 .{ }^{20}$ Studies using national survey data also indicated a comparable proportion of off-label use, which also included no mental health diagnosis, whereas office visits associated with an antipsychotic prescription served as the unit of analysis vs individual patients. ${ }^{18}$

In addition, there was a difference between our estimates of no mental health diagnosis (6.0\%-7.7\%) and 2 recent studies using the National Ambulatory Medical Care Survey (NAMCS) that reported approximately $15.0 \%$ of visits with patients who had an antipsychotic prescription did not have a mental disorder diagnosis. ${ }^{1,18}$ This notable difference could be related to the design of the NAMCS survey form, which could only capture up to 3 diagnoses. Thus, the inability to include more diagnoses could result in an underreporting of diagnoses and an overestimation of treatment visits with no diagnosis. Consistent with previous analysis, a higher proportion of males received antipsychotic prescriptions than females, and nearly all children and adolescents were prescribed SGAs vs FGAs.

The sensitivity analyses showed that the declining trend in off-label use was robust. Using this more broad definition (antipsychotic class vs individual level) of off-label use during 2013-2016, prevalence of off-label use 


\begin{tabular}{|c|c|c|c|}
\hline \multirow{2}{*}{$\begin{array}{c}\text { TABLE } 5 \\
\begin{array}{c}\text { Factor } \\
\text { [reference } \\
\text { group] }\end{array}\end{array}$} & \multicolumn{3}{|c|}{$\begin{array}{l}\text { Logistic Regression Analysis of Factors } \\
\text { Associated with Off-Label/No Diagnosis } \\
\text { Antipsychotic Use in } 2015(\mathrm{~N}=36,320)\end{array}$} \\
\hline & Odds ratio & $95 \% \mathrm{Cl}$ & $P$ value \\
\hline \multicolumn{4}{|c|}{ Age group [15-17], years } \\
\hline $5-9$ & 3.66 & $3.43-3.91$ & $<0.01$ \\
\hline $10-14$ & 1.26 & $1.19-1.33$ & $<0.01$ \\
\hline \multicolumn{4}{|c|}{ Antipsychotic type [FGAs] } \\
\hline SGAs & 0.43 & $0.35-0.54$ & $<0.01$ \\
\hline \multicolumn{4}{|l|}{ Sex [Female] } \\
\hline Male & 0.99 & $0.94-1.04$ & 0.67 \\
\hline
\end{tabular}

ranged from $60.9 \%-69.1 \%$, which was lower than the $75.9 \%$ reported by Leslie et al in 2003, which could be the result of more indications that were approved during the present study's time frame. ${ }^{19}$ Leslie et al indicated that the only FDA-approved indications were schizophrenia and bipolar disorders at that time. More indications such as autistic disorders and Tourette syndrome have been approved over time. Risperidone (2006) and aripiprazole (2009) were approved for irritability autistic disorders. Aripiprazole was approved for Tourette syndrome for children (aged $\geq 6$ years) at the end of 2014.

While the prevalence of off-label use is high, off-label use in the pediatric population is not uncommon in practice. Because of ethical considerations regarding the inclusion of children in clinical trials, many drugs are not tested in children and thus are not approved by the FDA in this population. ${ }^{37}$ Effectiveness and safety have not been well established for off-label use in this vulnerable population. In this study, approximately two-thirds of off-label use was supported by evidence in practice guidelines. ${ }^{25}$ However, using data from a survey of physicians regarding antipsychotic prescribing among Vermont Medicaid children, Rettew et al reported that while $72.8 \%$ of antipsychotics use were off label, $91.7 \%$ of this use followed the indications described in the best practice guidelines. ${ }^{7}$

Similar to previous literature, almost one-third (31.8\%) of antipsychotic-treated children had a diagnosis of ADHD, which was the most common off-label indication in this study. Sohn et al found that $24 \%$ of antipsychotic-related treatment visits were associated with ADHD. ${ }^{18}$ In Vermont Medicaid children, mood disorder (37.2\%) and ADHD (32.0\%) were the most common target conditions for antipsychotic prescriptions. ${ }^{7}$ Risperidone, which has demonstrated efficacy with a low strength of evidence ${ }^{24}$ was recommended for treating ADHD, combined with aggression by AACAPAAA and by Texas Children's Medication Algorithm only when no response to behavioral intervention and psychostimulants. ${ }^{25,38}$ In addition, risperidone was approved in Europe for short-term medication for aggression in conduct disorder in children aged 5 years and older. ${ }^{17}$

This reduction in off-label use in Texas Medicaid children could be explained by several factors. Safety concerns among prescribers increased, since mounting evidence showed SGA-induced adverse effects ${ }^{39}$ such as cardiovascular risks and metabolic effects among young people..$^{14,15,20}$ Several practice guidelines were released to inform appropriate usage of antipsychotics in 2011. The Agency for Healthcare Research and Quality updated its review of the off-label use of SGAs, and the AACAP issued the Practice Parameter to provide recommendations for antipsychotic use in children. ${ }^{24,25}$

In addition, since 2005, the Texas Department of State Health Services has released best practices annually, which provide guidance on prescribing psychotropic medication and adverse effect monitoring. ${ }^{39}$ Also, Texas Medicaid implemented a range of policies, including drug utilization reviews ${ }^{40}$ which resulted in a decline of overall antipsychotic prescriptions in Texas since implementation in $2005 .{ }^{26}$ As of June 2011, Texas Medicaid issued prior authorization policies for prescribing antipsychotics in children under 3 years. ${ }^{41}$ These national and state policies may have contributed to the decreases in off-label antipsychotic prescribing that were observed in this study.

The logistic regression indicated several factors associated with antipsychotic off-label use, including younger age groups and receiving FGAs. Not surprisingly, younger children were more likely to receive antipsychotics off label, since there is a paucity of antipsychotics approved for young children. Although not examined in children, a Georgia Medicaid study showed that FGAs were more likely to be used off label. ${ }^{27}$ In this study, there were no sex differences in off-label use among children, whereas Leslie et al showed that male sex increased the odds of receiving an off-label antipsychotic prescription. ${ }^{19}$

This study provided on-label vs off-label antipsychotic use patterns in a Medicaid pediatric population. A rigorous definition for on-label use was adopted based on indications approved for individual antipsychotic agents and corresponding age groups. This study further categorized off label into supported and unsupported use. 


\section{LIMITATIONS}

Several limitations associated with this study should be noted. First, the study population was Texas Medicaid children and adolescents, which limits generalizability to the general population, Medicaid-enrolled children in other states, and children covered by private insurance. Based on 2013-2016 data, this off-label pattern may have changed in recent years because of the introduction of new antipsychotics and changes in psychiatry practice.

Second, when using administrative claims data, it was difficult to determine which mental health disorder or related symptom (eg, aggression in behavior disorder) the antipsychotic was intended to treat. Diagnoses of mental health disorders in the same calendar year were identified and assumed to be associated with the index antipsychotic prescription; however, it was unknown if this was valid, since indications may have occurred outside of the study period. For patients who had multiple diagnoses, the diagnosis on the date that was closest to the prescription date in the same calendar year was used. For patients who had at least 1 on-label indication, a hierarchical classifying approach was adopted; for those who had no on-label indications, all diagnoses were reported.

Third, although DrugDex and practice guidelines were used to classify supported and unsupported off-label use, it was not possible to determine the appropriateness of other antipsychotic off-label use. For example, AACAP-AAA recommended that SGAs should be considered only if psychosocial and pharmacological interventions failed. ${ }^{25}$ Because of the limitations of administrative claims data, information regarding whether psychosocial alternatives were used before antipsychotic off-label use or whether patients failed to respond to specific antipsychotics was not available to assess the rationale for off-label prescribing. For example, we excluded behavioral problems and hyperactivity because they were only approved for specific drugs after failure to respond to other interventions, which is difficult to verify using claims data. However, a post hoc analysis including these diagnoses resulted in minimal changes to our results.

Fourth, for patients who switched antipsychotics, an intent-to-treat approach using the index drug was used, which may have under- or overestimated the proportion of off-label use. Also, the results could not be generalized to patients who were on combination therapy, since they typically represent patients with higher disease severity. However, this group represented only about $3 \%$ of the population.

Finally, other demographic (eg, race) and clinical (eg, health care provider type and access to psychotherapy) data were not available, which may be important in further characterizing off-label use. Leslie et al indicated that patients who were Black or Hispanic were less likely to have off-label use, which was also congruent with a study by Chen et al that examined the Georgia Medicaid adult population..$^{19,27}$

There is no consensus regarding whether physician specialty affects off-label prescribing. Some studies indicated that psychiatrists were more likely to prescribe antipsychotics for off-label indications compared with nonpsychiatrists, ${ }^{27,42}$ whereas Rettew et al found that the difference between psychiatrists and nonpsychiatrists was not significant.?

In December 2019, the Substance Abuse and Mental Health Services Administration released Guidance on Strategies to Promote Best Practice in Antipsychotic Prescribing for Children and Adolescents. ${ }^{26}$ Further studies are needed to evaluate the impact of implementing this guideline for offlabel use. The pediatric population, an underserved Medicaid population, are at increased risk for adverse events associated with antipsychotic use. In Texas Medicaid, it was important to examine trends after psychotropic medication-monitoring programs commenced. Thus, continual monitoring of off-label use, as well as diagnoses associated with off-label use should be monitored over time so that policies and procedures can be implemented to targeted groups.

\section{Conclusions}

Off-label use of antipsychotics in Texas Medicaid was common but declined during 2013-2016. Over one-half (51.6\%) of children receiving antipsychotic off-label prescriptions had a diagnosis of ADHD in 2015. Of those with off-label use, approximately two-thirds may have had supported indications. Younger children and those prescribed FGAs were more likely to receive an off-label antipsychotic prescription.

\section{DISCLOSURES}

No outside funding supported this study. The authors have nothing to disclose.

This study was presented as an abstract at the American Academy of Child and Adolescent Psychiatry's 67th Annual Meeting (Virtual), October 2020.

\section{REFERENCES}

1. Olfson M, Blanco C, Liu S-M, Wang S, Correll CU. National trends in the officebased treatment of children, adolescents, and adults with antipsychotics. Arch Gen Psychiatry. 2012;69(12):1247-56.

2. Cooper WO, Hickson GB, Fuchs C, Arbogast PG, Ray WA. New users of antipsychotic medications among children enrolled in TennCare. Arch Pediatr Adolesc Med. 2004;158(8):753-59. 
3. Alexander GC, Gallagher SA, Mascola A, Moloney RM, Stafford RS. Increasing off-label use of antipsychotic medications in the United States, 19952008. Pharmacoepidemiol Drug Saf. 2011;20(2):177-84.

4. Patel NC, Crismon ML, Hoagwood K, et al. Trends in the use of typical and atypical antipsychotics in children and adolescents. J Am Acad Child Adolesc Psychiatry. 2005;44(6):548-56.

5. Olfson M, King M, Schoenbaum M. Treatment of young people with antipsychotic medications in the United States. JAMA Psychiatry. 2015;72(9):867-74.

6. Edelsohn GA, Karpov I, Parthasarathy M, et al. Trends in antipsychotic prescribing in Medicaid-eligible youth. J Am Acad Child Adolesc Psychiatry. 2017;56(1):59-66.

7. Rettew DC, Greenblatt J, Kamon J, et al. Antipsychotic medication prescribing in children enrolled in Medicaid. Pediatrics. 2015;135(4):658-65.

8. Greene M, Paladini L, Lemmer T, Piedade A, Touya M, Clark O. Systematic literature review on patterns of pharmacological treatment and adherence among patients with bipolar disorder type I in the USA. Neuropsychiatr Dis Treat. 2018;14:1545-59.

9. Abou-Setta A, Mousavi S, Spooner C, et al. First-generation versus secondgeneration antipsychotics in adults: comparative effectiveness. Comparative Effectiveness Review No. 63. AHRQ Publication No. 12-EHC054-EF. Agency for Healthcare Research and Quality. August 2012. Accessed July 9, 2021. https://effectivehealthcare.ahrq.gov/ sites/default/files/pdf/antipsychoticsadults_research.pdf

10. Yang M, Barner JC, Lawson KA, et al. Antipsychotic medication utilization trends among Texas veterans: 1997-2002. Ann Pharmacother. 2008;42(9):1229-38.

11. Aparasu RR, Bhatara V, Gupta S. US national trends in the use of antipsychotics during office visits, 1998-2002. Ann Clin Psychiatry. 2005;17(3):147-52.
12. Yoon Y, Rubin DM, Riddle MA, Noll E, Rothbard A. Antipsychotic treatment among youth in foster care. Pediatrics. 2011;128(6):e1459-e1466.

13. Ray WA, Stein CM, Murray KT, et al. Association of antipsychotic treatment with risk of unexpected death among children and youths. JAMA Psychiatry. 2019;76(2):162-71.

14. McIntyre RS, Jerrell JM. Metabolic and cardiovascular adverse events associated with antipsychotic treatment in children and adolescents. Arch Pediatr. 2008;162(10):929-35.

15. Correll CU, Manu P, Olshanskiy V, Napolitano B, Kane JM, Malhotra AK. Cardiometabolic risk of second-generation antipsychotic medications during first-time use in children and adolescents. JAMA. 2009;302(16):1765-73.

16. De Hert M, Detraux J. The urgent need for optimal monitoring of metabolic adverse effects in children and youngsters who take on-label or off-label antipsychotic medication. JAMA Psychiatry. 2018;75(8):771-72.

17. Vitiello B, Correll C, van Zwieten-Boot B, Zuddas A, Parellada M, Arango C. Antipsychotics in children and adolescents: increasing use, evidence for efficacy and safety concerns. Eur Neuropsychopharmacol. 2009;19(9):629-35.

18. Sohn M, Moga DC, Blumenschein K, Talbert J. National trends in off-label use of atypical antipsychotics in children and adolescents in the United States. Medicine (Baltimore). 2016;95(23):e3784.

19. Leslie DL, Rosenheck R. Off-label use of antipsychotic medications in Medicaid. Am J Manag Care. 2012;18(3):e109-17.

20. Crystal S, Olfson M, Huang C, Pincus $\mathrm{H}$, Gerhard T. broadened use of atypical antipsychotics: safety, effectiveness, and policy challenges: expanded use of these medications, frequently off-label has often outstripped the evidence base for the diverse range of patients who are treated with them. Health Aff (Millwood). 2009;28(Suppl 1):w770-w781.
21. Matone M, Localio R, Huang YS, Dosreis S, Feudtner C, Rubin D. The relationship between mental health diagnosis and treatment with second-generation antipsychotics over time: a national study of US Medicaid-enrolled children. Health Serv Res. 2012;47(5):1836-60.

22. Larson MJ, Miller K, Fleming KJ. Treatment with antidepressant medications in private health plans. Adm Policy Ment Health. 2007;34(2):116-26.

23. Penfold RB, Stewart C, Hunkeler EM, et al. Use of antipsychotic medications in pediatric populations: what do the data say? Curr Psychiatry Rep. 2013;15(12):426.

24. Maglione M, Maher AR, Hu J, et al. Off-label use of atypical antipsychotics: an update. Comparative Effectiveness Reviews, No. 43. Agency for Healthcare Research and Quality. September 2011. Accessed July 9, 2021. https://www.ncbi. nlm.nih.gov/books/NBK66074/

25. Findling R, Drury S, Jensen P, et al. Practice parameter for the use of atypical antipsychotic medications in children and adolescents. American Academy of Child and Adolescent Psychiatry. 2011. Accessed July 9, 2021. https://www. aacap.org/App_Themes/AACAP/docs/ practice parameters/Atypical antipsychotic Medications Web.pdf

26. Substance Abuse and Mental Health Services Administration. Guidance on Strategies to Promote Best Practice in Antipsychotic Prescribing for Children and Adolescents. HHS Publication No. PEP19-ANTIPSYCHOTIC-BP. 2019. Accessed July 9, 2021. https://store. samhsa.gov/sites/default/files/d7/priv/ pep19-antipsychotic-bp_508.pdf

27. Chen H, Reeves JH, Fincham JE, Kennedy WK, Dorfman JH, Martin BC. Off-label use of antidepressant, anticonvulsant, and antipsychotic medications among Georgia Medicaid enrollees in 2001. J Clin Psychiatry. 2006;67(6):972-82.

28. Kogut SJ, Yam F, Dufresne R. Prescribing of antipsychotic medication in a Medicaid population: use of polytherapy and off-label dosages. J Manag Care Pharm. 2005;11(1):17-24. doi: 10.18553/ jmcp.2005.11.1.17 
29. Crystal S, Mackie T, Fenton MC, et al. Rapid growth of antipsychotic prescriptions for children who are publicly insured has ceased, but concerns remain. Health Aff (Millwood). 2016;35(6):974-82.

30. Grow HMG, Cook AJ, Arterburn DE, Saelens BE, Drewnowski A, Lozano P. Child obesity associated with social disadvantage of children's neighborhoods. Soc Sci Med. 2010;71(3):584-91.

31. Hurt L, Pinto CD, Watson J, et al. Diagnosis and screening for obesityrelated conditions among children and teens receiving Medicaid-Maryland, 2005-2010. MMWR Morb Mortal Wkly. 2014;63(14):305-08.

32. Morrato EH, Dodd S, Oderda G, Haxby DG, Allen R, Valuck RJ. Prevalence, utilization patterns, and predictors of antipsychotic polypharmacy: experience in a multistate Medicaid population, 19982003. Clin Ther. 2007;29(1):183-95.

33. Correll CU, Gallego JA. Antipsychotic polypharmacy: a comprehensive evaluation of relevant correlates of a longstanding clinical practice. Psychiatr Clin North Am. 2012;35(3):661-81.

34. IBM Micromedex® DRUGDEX® (electronic version). IBM Watson Health. Accessed February 17, 2021. https://www. micromedexsolutions.com/
35. Murphy TK, Lewin AB, Storch EA, Stock S. Practice parameter for the assessment and treatment of children and adolescents with tic disorders. J Am Acad Child Adolesc Psychiatry. 2013;52(12):1341-359.

36. McClellan J, Stock S. Practice parameter for the assessment and treatment of children and adolescents with schizophrenia. J Am Acad Child Adolesc Psychiatry. 2013;52(9):976-90.

37. Carrier F, Banayan D, Boley R, Karnik N. Ethical challenges in developing drugs for psychiatric disorders. Prog Neurobiol. 2017;152:58-69.

38. Pliszka S, Crismon M, Hughes C, et al. The Texas Children's Medication Algorithm Project: revision of the algorithm for pharmacotherapy for attention-deficit/hyperactivity disorder. J Am Acad Child Adolesc Psychiatry. 2006;45(6):642-57.

39. The Parameters Workgroup of the Psychiatric Executive Formulary Committee, Health and Specialty Care Division, Texas Health and Human Services Commission. Psychotropic medication utilization parameters for children and youth in Texas public behavioral health. June 2019. Accessed July 9, 2021. https://www.hhs.texas. gov/sites/default/files/documents/ doing-business-with-hhs/providerportal/facilities-regulation/psychiatric/ psychotropic-medication-utilizationparameters.pdf
40. Stein BD, Leckman-Westin E, Okeke E, et al. The effects of prior authorization policies on Medicaid-enrolled children's use of antipsychotic medications: evidence from two mid-Atlantic states. J Child Adolesc Psychopharmacol. 2014;24(7):374-81.

41. Schmid I, Burcu M, Zito JM. Medicaid prior authorization policies for pediatric use of antipsychotic medications. JAMA. 2015;313(9):966-68.

42. Ramachandran S, Banahan III BF, Bentley JP, West-Strum DS, Patel AS. Factors influencing the use of secondgeneration antipsychotics in children with psychosis. J Manag Care Spec Pharm. 2016;22(8):948-57. doi: 10.18553/ jmcp.2016.22.8.948 